\title{
Allergen exposure in infancy and the development of sensitization, wheeze, and asthma at 4 years
}

\author{
Jessica E. Brussee, MSc, ${ }^{a, b}$ Henriette A. Smit, PhD, ${ }^{a, b}$ Robert T. van Strien, PhD, ${ }^{c}$ \\ Karen Corver, MD, ${ }^{d}$ Marjan Kerkhof, MD, PhD, ${ }^{e}$ Alet H. Wijga, PhD, \\ Rob C. Aalberse, PhD, ${ }^{f}$ Dirkje Postma, MD, PhD, ${ }^{g}$ Jorrit Gerritsen, MD, PhD, ${ }^{\text {h }}$ \\ Diederick E. Grobbee, MD, PhD, ${ }^{b}$ Johan C. de Jongste, MD, PhD, ${ }^{d}$ and \\ Bert Brunekreef, PhD' Bilthoven, Utrecht, Rotterdam, Groningen, and Amsterdam, \\ The Netherlands, and Munich, Germany
}

Background: The relationship between mite and pet allergen exposure in infancy and the subsequent development of sensitization and asthma is complex.

Objective: We prospectively investigated the effect of allergen exposure at 3 months of age on the development of sensitization, wheeze, and physician-diagnosed asthma in the first 4 years of life in a birth cohort of children with and without an atopic mother.

Methods: Children participated in the Prevention and Incidence of Asthma and Mite Allergy study. Allergen exposure at 3 months of age was determined from mattress dust samples. Specific IgE to inhalant allergens was measured at 4 years of age, and information about wheeze and physician-diagnosed asthma was collected with yearly questionnaires.

Results: Mite and cat allergen exposure in infancy were associated with an increased risk of specific sensitization to house dust mite and cat, respectively, at 4 years of age. There were borderline significant associations between cat allergen exposure and persistent wheeze in the total study population and between dog allergen exposure and persistent wheeze in children with a nonatopic mother. In children with an atopic

From athe Center for Prevention and Health Services Research, National Institute for Public Health and the Environment, Bilthoven; ${ }^{b}$ the Julius Center for Health Sciences and Primary Care, Utrecht University Medical Center, Utrecht; ${ }^{c}$ the Institute for Occupational and Environmental Medicine, Ludwig-Maximilians-University, Munich; ${ }^{d}$ the Department of Pediatrics, Division of Respiratory Medicine, Erasmus MC-Sophia,

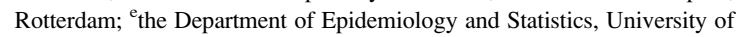
Groningen, Groningen; ${ }^{\mathrm{f}}$ the Department of Immunopathology, Sanquin Research at CLB, Amsterdam; ${ }^{\mathrm{g}}$ the Department of Pulmonology, University Hospital Groningen, Groningen; ${ }^{\mathrm{h}}$ the Department of Paediatric Respiratory Medicine, University Hospital Groningen, Groningen; and the Institute for Risk Assessment Sciences, Utrecht University, Utrecht.

Supported by the Netherlands Organisation for Health Research and Development; the Netherlands Organisation for Scientific Research; the Netherlands Asthma Fund; the Netherlands Ministry of Spatial Planning, Housing, and the Environment; and the Netherlands Ministry of Health, Welfare and Sport.

Disclosure of potential conflict of interest: All authors-none disclosed.

Received for publication October 18, 2004; revised February 18, 2005; accepted for publication February 24, 2005.

Reprint requests: Henriette A. Smit, PhD, National Institute for Public Health and the Environment (RIVM), Center for Prevention and Health Services Research (pigeonhole 101), PO Box 1, 3720 BA Bilthoven, the Netherlands. E-mail: jet.smit@rivm.nl.

0091-6749/\$30.00

(C) 2005 American Academy of Allergy, Asthma and Immunology doi:10.1016/j.jaci.2005.02.035 mother, there was some indication of a positive association between mite allergen exposure and physician-diagnosed asthma.

Conclusion: Early house dust mite and cat allergen exposure might lead to sensitization and, in case of cat allergen exposure, to persistent wheeze. Early mite and dog allergen exposure might lead to asthma and persistent wheeze, respectively, but only in subgroups defined by maternal atopy. (J Allergy Clin Immunol 2005;115:946-52.)

Key words: Cohort studies, child, preschool, allergens, house dust mites, cats, dogs, sensitization, wheezing, asthma

It remains unclear to what extent allergen exposure in infancy leads to sensitization and whether continued allergen exposure leads to the development of airway inflammation, airway hyperresponsiveness, and asthma. ${ }^{1,2}$ Population-based cohort studies are required to clarify this issue. ${ }^{3}$

Recently, several cohort studies have published results concerning the association between house dust mite and pet allergen exposure and the development of sensitization and asthma. With respect to sensitization, the Multicenter Atopy Study reported a clear association of mite and cat allergen exposure and sensitization in children. ${ }^{4,5}$ The Childhood Allergy Study showed that exposure to high levels of mite allergen increased the risk of sensitization in children with atopic parents, whereas it decreased the risk in children without atopic parents. ${ }^{6}$ Other studies showed no relationship between mite, cat, or dog allergen exposure and the development of sensitization. ${ }^{7,8}$

With respect to asthma, Sporik et $\mathrm{al}^{9}$ reported that exposure to high levels of mite allergens in early childhood was associated with an increased risk of asthma at 11 years of age. However, these results were not confirmed by later studies in children up to 7 years of age. ${ }^{5,6,8,10-12}$ Also, although some studies show no effect of cat and dog allergen exposure on the development of asthma, $5,8,10$ others show different effects for children with and without a family history of atopy. ${ }^{11,13}$

Studies with indirect measures of allergen exposure, such as the presence of cats or dogs in the home, showed protective effects on the development of sensitization and asthma. ${ }^{14-18}$ However, because the presence of pets in the 
home is a relatively poor measure of pet allergen exposure, these studies will not be discussed further. ${ }^{19}$

Among the above-mentioned studies, some investigated selected groups of children at high risk of sensitization or asthma because of an atopic or asthmatic family member ${ }^{7,9,10,13}$ or high cord blood IgE levels. ${ }^{12}$ Others have not presented their results for high-risk and low-risk children separately. ${ }^{5}$ Because a family history of asthma and allergies might influence the risk of sensitization or allergic symptoms in children, ${ }^{20}$ it seems important to study children at high risk and low risk of asthma separately. $^{21}$

In the Prevention and Incidence of Asthma and Mite Allergy study, quantitative information about exposure to house dust mite, cat, and dog allergens was collected at 3 months of age in a birth cohort of children at low risk or high risk for the development of allergy and asthma because of an allergic mother. In this article we prospectively investigated the effect of allergen exposure at 3 months of age on the development of sensitization, wheeze, and physician-diagnosed asthma in the first 4 years of life in children with and without an atopic mother.

\section{METHODS}

\section{Study design}

The Prevention and Incidence of Asthma and Mite Allergy study is a prospective birth cohort study that included 4146 children. Children were recruited from the general population through prenatal clinics in 3 regions of the Netherlands (the western, middle, and northern parts). During pregnancy, the mothers completed a validated screening questionnaire on asthma and inhalant allergies, ${ }^{22}$ from which their atopic status was determined. On the basis of the atopy of the mother, children were labeled as high risk (atopic mother, $\mathrm{n}=1327$ ) and low risk (nonatopic mother, $\mathrm{n}=2819$ ). Some of the children with an atopic mother $(\mathrm{n}=855)$ participated in an intervention study and received active or placebo mattress covers. The remaining children with an atopic mother and all children with a nonatopic mother participated in the natural history study and received no intervention.

At the start of the study, all children with an atopic mother and a random sample of the children with a nonatopic mother $(n=663)$ were selected for close follow-up, including a home visit at 3 months of age and a medical examination at 4 years of age. At 3 months of age, dust samples were collected from the child's mattress to determine exposure to house dust mite, cat, and dog allergens. At 4 years of age, blood samples were drawn to determine specific IgE levels to inhalant allergens. Data on demographic factors, respiratory symptoms, and risk factors for asthma were collected by using yearly questionnaires.

A detailed description of the study design has been published. ${ }^{23}$ The study protocol was approved by the medical ethics committees of the participating institutions. All parents provided written informed consent.

\section{Study population}

In the current article only the children who participated in the natural history study were included in the analyses. From the 3291 children who participated in the natural history study, 1127 children (atopic mother, 464; nonatopic mother, 663) were selected for close follow-up. Complete information about allergen exposure plus specific IgE, wheeze, or asthma was available for 365,849 , and 881
TABLE I. General characteristics of the study population

\begin{tabular}{lccc}
\hline & \multicolumn{2}{c}{$\begin{array}{c}\text { Children with complete } \\
\text { information* }\end{array}$} \\
\cline { 2 - 4 } & $\begin{array}{c}\text { Sensitization } \\
\text { (n = 365) }\end{array}$ & $\begin{array}{c}\text { Wheeze } \\
\text { (n = 849) }\end{array}$ & $\begin{array}{c}\text { Asthma } \\
\text { (n = 881) }\end{array}$ \\
\hline Atopic mother, \% & 44 & 41 & 41 \\
Sex, \% boys & 46 & 49 & 49 \\
Study region, \% & & & \\
$\quad$ North & 30 & 31 & 31 \\
$\quad$ West & 27 & 25 & 25 \\
$\quad$ Middle & 44 & 44 & 44 \\
Education of the mother, \% & & & \\
$\quad$ Low & 22 & 22 & 21 \\
$\quad$ Middle & 42 & 43 & 44 \\
$\quad$ High & 36 & 35 & 35 \\
Older siblings, \% & 57 & 49 & 48 \\
Contact with other & & & \\
$\quad$ children (first year), \% & & & \\
$\quad$ Small number (family, & 44 & 41 & 41 \\
$\quad$ babysitter) & & & \\
$\quad$ Large number (daycare) & 22 & 24 & 24 \\
Exposure to ETS (first year), \% & 27 & 24 & 25 \\
\hline
\end{tabular}

ETS, Environmental tobacco smoke.

*All children with close follow-up for whom information was available about allergen exposure at 3 months of age plus information about sensitization, wheeze, or physician-diagnosed asthma at 4 years of age in combination with nonmissing values for possible confounders.

children, respectively (only children with nonmissing values for possible confounders). A detailed flow chart of the study population has been included in the Journal's Online Repository (see Fig E1 at www.mosby.com/jaci).

\section{Dust samples}

A detailed description of the methods for dust collection has been published. ${ }^{24}$ Dust extracts were analyzed for Der p 1, Der f 1, Fel d 1, and Can $\mathrm{f} 1$ allergens, and allergen exposure was expressed in nanograms per square meter of bed surface. ${ }^{25}$ Because dust samples were taken all through the year and season is known to influence house dust mite allergen levels, mite allergen levels were adjusted for season by using a correction factor, as previously described. ${ }^{24}$ For Der $\mathrm{p} 1$, the correction factors were 0.8 for winter, spring, and summer compared with autumn. For Der f 1 , the correction factors were $0.8,0.6$, and 1.0 , respectively. Total house dust mite exposure (Der 1) was calculated as Der $\mathrm{p} 1$ plus Der $\mathrm{f} 1$.

\section{Specific IgE}

Specific IgE to inhalant allergens (house dust mite, cat, and dog) was determined by means of RAST at 4 years of age. Sensitization of the child to a specific allergen was defined as a specific $\operatorname{IgE}$ concentration of greater than $0.35 \mathrm{IU} / \mathrm{mL}$ for that allergen.

\section{Questionnaire data}

In the yearly questionnaires symptoms of wheeze were assessed by core questions from the International Study of Asthma and Allergies in Childhood questionnaire. ${ }^{26}$ On the basis of the longitudinal data on wheeze symptoms collected yearly in the first 4 years of life, children were divided into 4 wheezing phenotypes ${ }^{27}$ : never wheeze; early transient wheeze (at least 1 episode of wheeze in the first 3 years of life and no wheeze in the fourth year of life); late-onset wheeze (no wheeze in the first 3 years of life and at least 1 episode of wheeze in the fourth year of life); and persistent wheeze (at least 1 episode of wheeze in the first 3 years of life and at least 1 episode of 
TABLE II. Percentages of children with nondetectable allergen levels in their mattress dust and median allergen levels within the tertiles of detectable allergen levels

\begin{tabular}{|c|c|c|c|c|c|c|c|c|}
\hline \multirow{2}{*}{$\begin{array}{l}\text { Allergen } \\
(\mathrm{ng} / \mathrm{m})\end{array}$} & \multirow[b]{2}{*}{$n^{*}$} & \multirow[b]{2}{*}{$\mathrm{ND} \dagger(\%)$} & \multicolumn{2}{|c|}{ 1st tertile } & \multicolumn{2}{|c|}{ 2nd tertile } & \multicolumn{2}{|r|}{ 3rd tertile } \\
\hline & & & $\mathbf{n}$ & Median (range) $\$$ & $\mathbf{n}$ & Median (range) & $\mathbf{n}$ & Median (range) $\dot{\ddagger}$ \\
\hline Der 1 & 971 & 42 & 187 & $113(21-224)$ & 188 & $407(225-819)$ & 188 & $1989(835-281,621)$ \\
\hline Fel d 1 & 988 & 13 & 286 & $13(2-33)$ & 285 & $91(33-306)$ & 286 & $667(311-3729)$ \\
\hline Can $\mathrm{f} 1$ & 982 & 68 & 106 & $332(125-614)$ & 107 & $1022(621-2143)$ & 106 & $4612(2149-29,880)$ \\
\hline
\end{tabular}

$* n$, Number of children for whom allergen exposure was determined.

$\dagger N D$, Nondetectable allergen levels; percentage of children with nondetectable allergen levels in their mattress dust.

$\ddagger$ Median allergen levels in the first, second, and third tertile of allergen exposure in nanograms per meter squared.

wheeze in the fourth year of life), as previously described. ${ }^{28}$ Information about physician-diagnosed asthma was collected by using the following questions: "Did a doctor ever diagnose asthma in your child?" and "Has your child had asthma in the last 12 months?" Children with a positive answer to both questions in the fourth year of life were labeled as having current asthma.

\section{Data analysis}

Multiple logistic regression analysis was used to study the association between allergen exposure (independent variable) and sensitization, wheeze, or asthma (dependent variables). Children with detectable allergen levels were divided into tertiles, whereas children with nondetectable allergen levels comprised the reference group.

Specific sensitization was analyzed in relation to exposure to the relevant allergens only (eg, cat sensitization was related to Fel d 1 exposure). In the analyses with wheeze as a dependent variable, children with early transient or persistent wheeze were compared with the children who never wheezed. Because of the small numbers of children with late-onset wheeze, these children were not taken into account.

As potential confounders, we considered atopy of the parents, sex, study region, education of the mother, presence of older siblings, contact with children other than siblings, and exposure to environmental tobacco smoke. Analyses were performed for the total study population and for children with and without an atopic mother separately.

All analyses were performed with SAS statistical software (version 8.2; SAS Institute, Cary, NC). $P$ values of less than .05 were considered to be statistically significant.

\section{RESULTS}

\section{General characteristics of the study population}

The general characteristics of the study population are shown in Table I. Among the children with complete information about sensitization $(\mathrm{n}=365), 14 \%, 7 \%$, and $4 \%$ had specific $\operatorname{IgE}$ to house dust mite, cat, or dog allergens, respectively (children with an atopic mother: $18 \%, 8 \%$, and $4 \%$; children with a nonatopic mother: $10 \%$, $7 \%$, and $4 \%$ ). Among the 849 children with complete information about wheeze, $24 \%$ and $11 \%$ had early transient and persistent wheeze, respectively (atopic mother: $26 \%$ and $14 \%$; nonatopic mother: $23 \%$ and $9 \%$ ). Among the 881 children with complete information about asthma, $4 \%$ had physician-diagnosed asthma at 4 years of age (atopic mother: 5\%; nonatopic mother: $4 \%$ ).

Compared with the children with complete information about allergen exposure and sensitization, children for whom complete information was not obtained less often had older siblings ( $44 \%$ vs $57 \%$ ). Compared with the children with complete information about allergen exposure and wheeze or asthma, children for whom complete information was not obtained were more often living in the western and northern parts of the Netherlands (wheeze: western part, $33 \%$ vs $25 \%$; northern part, $40 \%$ vs $31 \%$; asthma: western part, $35 \%$ vs $25 \%$; northern part, $39 \%$ vs $31 \%$ ) and less often in the middle part of the Netherlands.

\section{Allergen exposure}

Der 1, Fel d 1, and Can $\mathrm{f} 1$ allergen levels were less than the detection limit of the assay for $42 \%, 13 \%$, and $68 \%$ of the mattress dust samples, respectively (Table II). There were no major differences in the distribution of allergen exposure for children with and without an atopic mother.

\section{Allergen exposure and sensitization}

Fig 1 shows the prevalence of specific sensitization to mite, cat, and dog in the 4 exposure categories for the total study population and for children with an atopic or nonatopic mother separately. In the total study population, exposure to house dust mite and cat allergen increased the risk of specific sensitization to house dust mite and cat, respectively. Dog allergen exposure did not influence the risk of sensitization to dog. Similar results were observed for children with and without an atopic mother, although the association between cat allergen exposure and sensitization was not statistically significant for the children with an atopic mother (Table III).

\section{Allergen exposure and early transient wheeze}

In the total study population, exposure to mite, cat, or dog allergens was not significantly associated with early transient wheeze. If anything, mite allergen exposure was related to less transient wheeze $(P$ for trend $=.06)$. Similar associations were observed for children with an atopic mother. In children with a nonatopic mother, dog allergen exposure was associated with early transient wheeze (Table IV).

\section{Allergen exposure and persistent wheeze}

In the total study population, mite and dog allergen exposure were not associated with persistent wheeze. There was a borderline significant association between cat allergen exposure and persistent wheeze. In children with 
and without an atopic mother, similar tendencies were observed, although they were not statistically significant. In children with a nonatopic mother, there was a borderline significant association between dog allergen exposure and persistent wheeze (Table V).

\section{Allergen exposure and physician-diagnosed asthma}

In the total study population, house dust mite, cat, and dog allergen exposure were not associated with physiciandiagnosed asthma. In children with a nonatopic mother, similar results were observed. In children with an atopic mother, exposure to mite allergen showed a borderline significant association with physician-diagnosed asthma, whereas cat and dog allergen exposure were not associated with physician-diagnosed asthma (Table VI).

With respect to the associations between house dust mite allergen exposure and sensitization, wheeze, and asthma, data for Der p 1 and Der f 1 separately are presented in the Journal's Online Repository (Tables E1E4 at www.mosby.com/jaci).

\section{DISCUSSION}

In this prospective study among children from the general population, we observed that mite and cat allergen exposure in infancy were associated with an increased risk of specific sensitization to house dust mite and cat, respectively, at 4 years of age. The relationship between allergen exposure and symptom development was less clear. However, cat allergen exposure seemed to increase the risk of persistent wheeze, whereas dog allergen exposure increased the risk of either transient or persistent wheeze in the subgroup of children with a nonatopic mother. In children with an atopic mother, there was some indication of a positive association between mite allergen exposure and physician-diagnosed asthma.

To appreciate these findings, some issues need to be addressed. Selection bias might have occurred if the association between allergen exposure and sensitization, wheeze, or asthma was different for the children who were included in the analyses and those who were excluded because of missing information about exposure, sensitization, wheeze, asthma, or possible confounders. Among the children not included in the analyses for sensitization, there was a lower percentage of children with older siblings. Among the children not included in the analyses for wheeze and asthma, there was a higher percentage of children from the western and northern parts of the Netherlands. Because study region or the presence of older siblings are not likely to have a major influence on the association between allergen exposure and sensitization or symptoms, selection bias because of these aspects seems unlikely.

It might be argued that measurement of allergen levels in a reservoir like the bed does not accurately reflect the total allergen exposure of the child. However, because
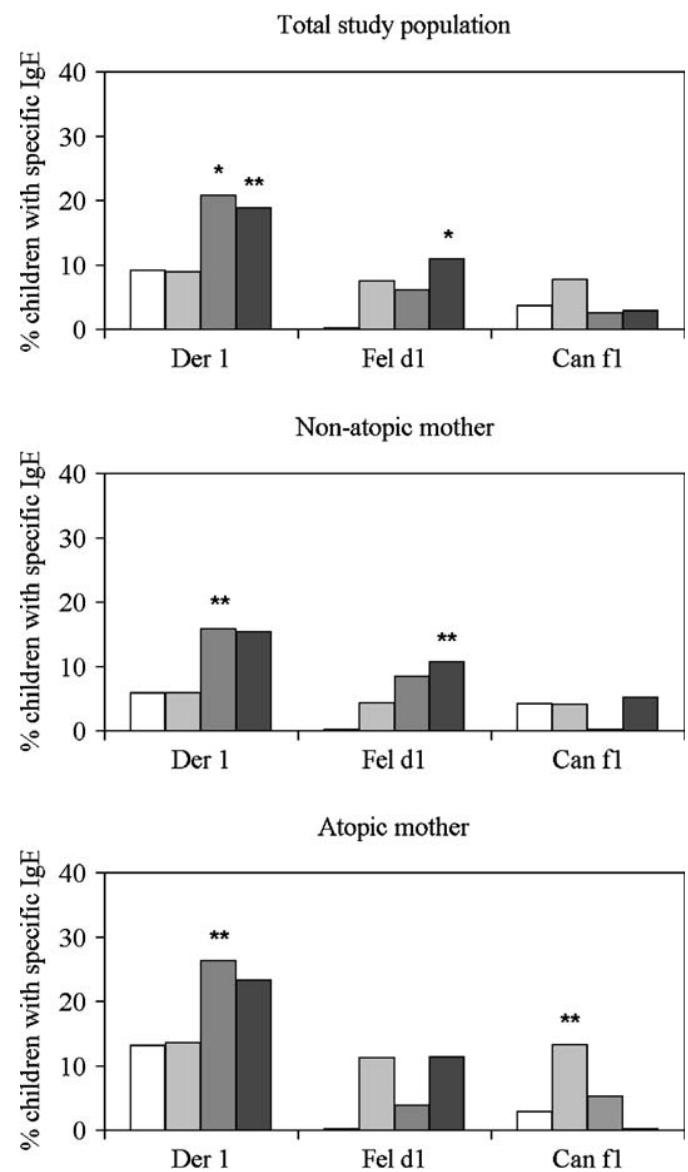

FIG 1. Percentage of children with specific lgE against mite (Der 1), cat (Fel d 1), or dog (Can $f 1$ ) by level of allergen exposure. Open columns, Nondetectable allergen exposure; lightly shaded columns, first tertile of allergen exposure; heavily shaded columns, second tertile of allergen exposure; filled columns, third tertile of allergen exposure. ${ }^{*} P<.05$ compared with nondetectable allergen exposure. ${ }^{*} P<.10$ compared with nondetectable allergen exposure.

3-month-old children spend most of their time in bed, this might be the best approximation to measure allergen exposure for this age category. Although some misclassification is possible, this would decrease our chance of finding significant associations rather than producing spurious ones.

Within our study population, there was a large percentage of children with nondetectable allergen levels in their mattress dust, especially for mite and dog allergens. An explanation for the low levels of mite allergens might be that about one third of the children had a new mattress at the time of birth. ${ }^{24}$

Another explanation might be that during the winters of 1995-1996 and 1996-1997, which preceded sampling in the large majority of the houses, temperatures were unseasonably low in the Netherlands, which likely decreased the amount of dust mites in the homes (Royal Netherlands Meteorological Institute, monthly and yearly mean temperatures). The low levels of dog allergen 
TABLE III. Adjusted odds ratios for the presence of sensitization in the 3 tertiles of allergen exposure compared with children with nondetectable allergen levels

\begin{tabular}{llll} 
& \multicolumn{3}{c}{$\mathbf{1}^{\text {st }}$ tertile } \\
\cline { 2 - 4 } ND, $n$ & $\mathbf{n}$ & OR & $95 \% \mathrm{Cl}^{*}$ \\
population & &
\end{tabular}

\begin{tabular}{|c|c|c|c|c|c|c|c|c|c|c|c|}
\hline \multicolumn{12}{|c|}{ Total study population } \\
\hline Der 1 & 153 & 56 & 1.30 & $0.42-4.02$ & 82 & $3.22 \S$ & $1.37-7.57$ & 69 & $3.05 \S$ & $1.19-7.84$ & .01 \\
\hline Fel d $1 \dagger$ & 40 & 121 & 1.00 & - & 98 & 1.13 & $0.37-3.43$ & 100 & 2.609 & $0.97-6.95$ & .06 \\
\hline Can f 1 & 245 & 39 & 2.02 & $0.45-9.07$ & 39 & 0.34 & $0.03-3.49$ & 34 & 0.52 & $0.06-4.86$ & .44 \\
\hline \multicolumn{12}{|c|}{ Nonatopic mother } \\
\hline Der 1 & 85 & 34 & 0.74 & $0.12-4.54$ & 44 & 2.88 & $0.81-10.30$ & 39 & 3.28 & $0.76-14.17$ & .05 \\
\hline Fel d $1 \dagger$ & 23 & 68 & 1.00 & - & 47 & 3.21 & $0.63-16.34$ & 65 & $5.76 \|$ & $1.23-26.93$ & .02 \\
\hline Can $\mathrm{f} 1$ & 140 & 24 & 1.38 & $0.12-16.32$ & 20 & $-t$ & - & 19 & 0.52 & $0.04-6.67$ & .27 \\
\hline \multicolumn{12}{|c|}{ Atopic mother } \\
\hline Der 1 & 68 & 22 & 1.89 & $0.40-8.92$ & 38 & $6.38 \S$ & $1.57-25.84$ & 30 & $4.61 \S$ & $1.06-20.01$ & .02 \\
\hline Fel d $1 \dagger$ & 17 & 53 & 1.00 & - & 51 & 0.40 & $0.06-2.48$ & 35 & 1.98 & $0.43-9.06$ & .50 \\
\hline Can $\mathrm{f} 1$ & 105 & 15 & $23.63 \S$ & $1.28-435$ & 19 & 7.03 & $0.34-147$ & 15 & -+ & - & .78 \\
\hline
\end{tabular}

$O R$, Odds ratio.

*Adjusted odds ratio $(95 \% \mathrm{CI})$. Adjusted for sex, study region, education of the mother, presence of older siblings, contact with children other than siblings, exposure to environmental tobacco smoke, and atopy of the parents (total study population)/atopy of the father (analyses stratified to atopy of the mother). $\dagger$ None of the children with nondetectable Fel d 1 allergen levels were sensitized to cat. Children with nondetectable allergen levels and children in the first tertile of allergen exposure were combined into one reference category to calculate odds ratios.

†In the second tertile of Can $\mathrm{f} 1$ exposure (nonatopic mother) and the third tertile of Can $\mathrm{f} 1$ exposure (atopic mother), there were no children with specific sensitization to dog.

$\S P<.05$ compared with children with nondetectable allergen exposure.

$\| P<.05$ compared with children in the nondetectable plus first tertile of allergen exposure categories.

$\mathbb{q} P<.10$ compared with children in the nondetectable plus first tertile of allergen exposure categories.

TABLE IV. Adjusted odds ratios for the presence of early transient wheeze in the 3 tertiles of allergen exposure compared with children with nondetectable allergen levels

\begin{tabular}{|c|c|c|c|c|c|c|c|c|c|c|c|}
\hline & \multirow[b]{2}{*}{ ND, $n$} & \multicolumn{3}{|c|}{ 1st tertile } & \multicolumn{3}{|c|}{ 2nd tertile } & \multicolumn{3}{|c|}{ 3rd tertile } & \multirow{2}{*}{$\begin{array}{c}P \text { value } \\
\text { for Trend }\end{array}$} \\
\hline & & $\mathbf{n}$ & OR & $95 \% \mathrm{Cl}^{*}$ & $\mathbf{n}$ & OR & $95 \% \mathrm{Cl}^{*}$ & $\mathbf{n}$ & OR & $95 \% \mathrm{Cl}^{*}$ & \\
\hline \multicolumn{12}{|c|}{ Total study population } \\
\hline Der 1 & 313 & 139 & 0.67 & $0.42-1.09$ & 142 & 0.77 & $0.48-1.22$ & 133 & $0.62 \dagger$ & $0.37-1.02$ & .06 \\
\hline Fel d 1 & 107 & 226 & 1.29 & $0.74-2.25$ & 210 & 1.14 & $0.64-2.00$ & 196 & 1.54 & $0.87-2.73$ & .21 \\
\hline Can $\mathrm{f} 1$ & 519 & 74 & 0.68 & $0.36-1.27$ & 73 & $1.60 \dagger$ & $0.94-2.73$ & 69 & 1.25 & $0.69-2.24$ & .20 \\
\hline \multicolumn{12}{|c|}{ Nonatopic mother } \\
\hline Der 1 & 188 & 90 & $0.55 \dagger$ & $0.29-1.04$ & 82 & 0.83 & $0.45-1.51$ & 81 & 0.63 & $0.32-1.22$ & .20 \\
\hline Fel d 1 & 66 & 137 & 1.00 & $0.48-2.06$ & 117 & 1.03 & $0.49-2.16$ & 129 & 1.64 & $0.80-3.35$ & .11 \\
\hline Can $\mathrm{f} 1$ & 315 & 46 & 0.99 & $0.46-2.14$ & 43 & $2.07 \$$ & $1.03-4.18$ & 44 & 1.61 & $0.77-3.36$ & .05 \\
\hline \multicolumn{12}{|c|}{ Atopic mother } \\
\hline Der 1 & 125 & 49 & 0.88 & $0.41-1.88$ & 60 & 0.66 & $0.31-1.40$ & 52 & 0.59 & $0.27-1.30$ & .15 \\
\hline Fel d 1 & 41 & 89 & 1.90 & $0.78-4.63$ & 93 & 1.37 & $0.54-3.44$ & 67 & 1.30 & $0.50-3.39$ & .89 \\
\hline Can $\mathrm{f} 1$ & 204 & 28 & $0.36 \dagger$ & $0.12-1.10$ & 30 & 1.40 & $0.59-3.32$ & 25 & 0.80 & $0.29-2.19$ & .90 \\
\hline
\end{tabular}

$O R$, Odds ratio.

*Adjusted odds ratio $(95 \% \mathrm{CI})$. Adjusted for sex, study region, education of the mother, presence of older siblings, contact with children other than siblings, exposure to environmental tobacco smoke, and atopy of the parents (total study population)/atopy of the father (analyses stratified to atopy of the mother).

$\dagger P<.10$ compared with children with nondetectable allergen levels.

$\ddagger P<.05$ compared with children with nondetectable allergen levels.

might be explained by the fact that only $16 \%$ of the children in the study population had a dog at home at 3 months of age.

In our study house dust mite allergen exposure was associated with an increased risk of sensitization. The finding of a dose-response association is in accordance with the results of other studies. The German Multicenter Atopy Study showed a positive association between exposure to house dust mite allergen in infancy and the induction of sensitization until 7 years of age. ${ }^{4,5}$
Cullinan et $\mathrm{al}^{8}$ found, in a study among British children, that the risk of sensitization increased at low levels of exposure (comparable with the levels in our study) but was attenuated at higher levels of exposure beyond the range that we were able to study. In a study from Michigan, house dust mite allergen exposure at 2 years of age tended to decrease the risk of specific sensitization to house dust mite at 6 to 7 years of age in children without a parental history of atopy, whereas it increased the risk in children with a parental history of atopy. ${ }^{6}$ In 
TABLE V. Adjusted odds ratios for the presence of persistent wheeze in the 3 tertiles of allergen exposure compared with children with nondetectable allergen levels

\begin{tabular}{|c|c|c|c|c|c|c|c|c|c|c|c|}
\hline & \multirow[b]{2}{*}{ ND, $n$} & \multicolumn{3}{|c|}{ 1st tertile } & \multicolumn{3}{|c|}{ 2nd tertile } & \multicolumn{3}{|c|}{ 3rd tertile } & \multirow{2}{*}{$\begin{array}{l}P \text { value } \\
\text { for Trend }\end{array}$} \\
\hline & & $\mathbf{n}$ & OR & $95 \% \mathrm{Cl}^{*}$ & $\mathbf{n}$ & OR & $95 \% \mathrm{Cl}^{*}$ & $\mathbf{n}$ & OR & $95 \% \mathrm{Cl}^{*}$ & \\
\hline \multicolumn{12}{|c|}{ Total study population } \\
\hline Der 1 & 256 & 130 & 1.38 & $0.77-2.50$ & 117 & 0.87 & $0.45-1.71$ & 113 & 0.66 & $0.32-1.36$ & .24 \\
\hline Fel d 1 & 90 & 195 & 1.97 & $0.85-4.55$ & 175 & 1.35 & $0.56-3.26$ & 164 & $2.31 \dagger$ & $0.98-5.46$ & .17 \\
\hline Can $\mathrm{f} 1$ & 435 & 73 & 1.69 & $0.86-3.31$ & 55 & 1.40 & $0.65-3.02$ & 59 & 1.72 & $0.82-3.63$ & .09 \\
\hline \multicolumn{12}{|c|}{ Nonatopic mother } \\
\hline Der 1 & 152 & 87 & 1.41 & $0.63-3.17$ & 66 & 0.83 & $0.31-2.25$ & 67 & 0.59 & $0.20-1.73$ & .31 \\
\hline Fel d 1 & 56 & 119 & 1.08 & $0.35-3.35$ & 98 & 0.93 & $0.29-3.03$ & 104 & 2.22 & $0.73-6.80$ & .11 \\
\hline Can $\mathrm{f} 1$ & 268 & 42 & 1.90 & $0.70-5.22$ & 30 & 1.31 & $0.40-4.32$ & 37 & $2.50 \dagger$ & $0.92-6.80$ & .08 \\
\hline \multicolumn{12}{|c|}{ Atopic mother } \\
\hline Der 1 & 104 & 43 & 1.27 & $0.50-3.18$ & 51 & 0.83 & $0.32-2.11$ & 46 & 0.76 & $0.29-2.03$ & .52 \\
\hline Fel d 1 & 34 & 76 & $3.52 \dagger$ & $0.92-13.37$ & 77 & 1.76 & $0.44-7.16$ & 60 & 2.21 & $0.55-8.91$ & .98 \\
\hline Can $\mathrm{f} 1$ & 167 & 31 & 1.58 & $0.61-4.09$ & 25 & 1.36 & $0.46-3.97$ & 22 & 1.09 & $0.32-3.65$ & .63 \\
\hline
\end{tabular}

$O R$, Odds ratio.

*Adjusted odds ratio $(95 \% \mathrm{CI})$. Adjusted for sex, study region, education of the mother, presence of older siblings, contact with children other than siblings, exposure to environmental tobacco smoke, and atopy of the parents (total study population)/atopy of the father (analyses stratified to atopy of the mother). $\dagger P<.10$ compared with children with nondetectable allergen levels.

TABLE VI. Adjusted odds ratios for the presence of physician-diagnosed asthma in the 3 tertiles of allergen exposure compared with children with nondetectable allergen levels

\begin{tabular}{|c|c|c|c|c|c|c|c|c|c|c|c|}
\hline & \multirow[b]{2}{*}{ ND, $n$} & \multicolumn{3}{|c|}{ 1st tertile } & \multicolumn{3}{|c|}{ 2nd tertile } & \multicolumn{3}{|c|}{ 3rd tertile } & \multirow{2}{*}{$\begin{array}{c}P \text { value } \\
\text { for Trend }\end{array}$} \\
\hline & & $\mathbf{n}$ & OR & $95 \% \mathrm{Cl}^{*}$ & $\mathbf{n}$ & OR & $95 \% \mathrm{Cl}^{*}$ & $\mathbf{n}$ & OR & $95 \% \mathrm{Cl}^{*}$ & \\
\hline \multicolumn{12}{|c|}{ Total study population } \\
\hline Der 1 & 370 & 169 & 1.18 & $0.42-3.29$ & 170 & 1.72 & $0.70-4.26$ & 154 & 1.87 & $0.75-4.68$ & .14 \\
\hline Fel d 1 & 118 & 269 & 1.48 & $0.46-4.72$ & 248 & 0.75 & $0.21-2.67$ & 242 & 1.92 & $0.60-6.14$ & .39 \\
\hline Can $\mathrm{f} 1$ & 603 & 91 & 1.10 & $0.36-3.33$ & 88 & 1.02 & $0.33-3.10$ & 89 & 1.20 & $0.39-3.71$ & .78 \\
\hline \multicolumn{12}{|c|}{ Nonatopic mother } \\
\hline Der 1 & 216 & 106 & 0.85 & $0.21-3.48$ & 98 & 1.33 & $0.40-4.44$ & 90 & 1.13 & $0.32-4.02$ & .73 \\
\hline Fel d 1 & 71 & 156 & 1.25 & $0.23-6.87$ & 137 & 0.47 & $0.06-3.56$ & 155 & 2.85 & $0.58-14.00$ & .12 \\
\hline Can $\mathrm{f} 1$ & 360 & 54 & 1.15 & $0.24-5.48$ & 50 & 0.91 & $0.18-4.48$ & 53 & 1.64 & $0.41-6.54$ & .60 \\
\hline \multicolumn{12}{|c|}{ Atopic mother } \\
\hline Der 1 & 154 & 63 & 2.10 & $0.43-10.16$ & 72 & 2.63 & $0.62-11.23$ & 64 & $3.52 \dagger$ & $0.87-14.21$ & .07 \\
\hline Fel d 1 & 47 & 113 & 1.68 & $0.33-8.63$ & 111 & 0.90 & $0.16-5.16$ & 87 & 1.02 & $0.17-6.22$ & .62 \\
\hline Can $\mathrm{f} 1$ & 243 & 37 & 1.04 & $0.21-5.18$ & 38 & 1.08 & $0.22-5.41$ & 36 & 0.62 & $0.07-5.23$ & .77 \\
\hline
\end{tabular}

$O R$, Odds ratio.

*Adjusted odds ratio $(95 \% \mathrm{CI})$. Adjusted for sex, study region, education of the mother, presence of older siblings, contact with children other than siblings, exposure to environmental tobacco smoke, and atopy of the father.

$\dagger P<.10$ compared with children with nondetectable allergen levels.

our study we did not observe much interaction with maternal atopy.

With respect to cat allergen exposure, we observed a higher risk of sensitization in children with a nonatopic mother and no association in children with an atopic mother. With respect to children with a nonatopic mother, these results are in accordance with the results from the German Multicenter Atopy Study. ${ }^{4,5}$ The absence of a dose-response association in children with an atopic mother might be explained by the fact that in children with a positive family history of allergy, low levels of allergen exposure might already be sufficient to cause sensitization. $^{4,7,8}$

In our study we did not observe an association between mite allergen exposure and persistent wheeze. This is in accordance with the results of others. ${ }^{5,8,11} \mathrm{We}$ did observe an association between cat allergen exposure and persis- tent wheeze, which was borderline significant for the total study population and showed similar trends for children with and without an atopic mother. For children with an atopic mother, these results are in accordance with those of other studies that do show an increased risk of wheeze in children with an asthmatic mother. ${ }^{11,13}$ With respect to our results in children with a nonatopic mother, Polk et $\mathrm{al}^{11}$ observed no effects of cat allergen exposure on the risk of wheeze for children with a nonasthmatic mother, whereas Celedon et $\mathrm{al}^{13}$ observed protective effects of cat allergen exposure. However, the latter study included only children with at least one parent with a history of asthma, which makes it difficult to compare their results with ours.

The results of studies investigating the association between mite allergen exposure and asthma are conflicting. In children with at least 1 atopic parent, Sporik et $\mathrm{al}^{9}$ 
showed an increased risk of asthma at 11 years of age with exposure to high concentrations of mite allergens $(10 \mu \mathrm{g}$ of allergen per gram of dust). The results of the Childhood Allergy Study, however, suggested a protective effect of these levels of mite allergen exposure on the risk of asthma at 6 to 7 years of age in children with a parental history of allergy. Also, the latter study showed that in children without a parental history of allergy or asthma, the risk of asthma was increased with high allergen exposure. In our study, in which the levels of mite allergen exposure were markedly lower, ${ }^{29}$ there was some indication of a positive association between Der 1 exposure and physician-diagnosed asthma at 4 years in children with an atopic mother but not in children with a nonatopic mother. The results of the Multicenter Atopy Study, which also studied low levels of allergen exposure, indicate that there is no effect of mite allergen exposure on the risk of asthma at 7 years of age. ${ }^{5}$

In conclusion, early house dust mite and cat allergen exposure might lead to sensitization and, in the case of cat allergen, persistent wheeze. Early mite and dog allergen exposure might lead to asthma and persistent wheeze, respectively, but only in subgroups defined by maternal atopy. The cohort needs to be followed further to assess the long-term consequences of early-life exposure to allergens.

We thank all the children and their parents for their cooperation. We also thank all field workers (Kees Venema, Ellen NoordaWiebrands, Tineke van der Veen, Henny Oosterloo, Wietske Winters, Mandy Routledge, Marieke Bolling, Laurens Koopman, Maaike Seesink, Marieke Oldenwening, Isabella Oosting, Siegfried de Wind, Jack Spithoven, Rob Beelen, Mariella Giovannangelo, and Marieke Siekmans), the data manager (Ada Vos), and the laboratory personnel (Janny de Vrieze) for their efforts.

\section{REFERENCES}

1. Murray CS, Woodcock A, Custovic A. The role of indoor allergen exposure in the development of sensitization and asthma. Curr Opin Allergy Clin Immunol 2001;1:407-12.

2. Platts-Mills TA, Rakes G, Heymann PW. The relevance of allergen exposure to the development of asthma in childhood. J Allergy Clin Immunol 2000;105(suppl):S503-8.

3. Pearce N, Douwes J, Beasley R. Is allergen exposure the major primary cause of asthma? Thorax 2000;55:424-31.

4. Wahn U, Lau S, Bergmann R, Kulig M, Forster J, Bergmann K, et al. Indoor allergen exposure is a risk factor for sensitization during the first three years of life. J Allergy Clin Immunol 1997;99:763-9.

5. Lau S, Illi S, Sommerfeld C, Niggemann B, Bergmann R, von Mutius E, et al. Early exposure to house-dust mite and cat allergens and development of childhood asthma: a cohort study. Multicentre Allergy Study Group. Lancet 2000;356:1392-7.

6. Cole Johnson C, Ownby DR, Havstad SL, Peterson EL. Family history, dust mite exposure in early childhood, and risk for pediatric atopy and asthma. J Allergy Clin Immunol 2004;114:105-10.

7. Munir AK, Kjellman NI, Bjorksten B. Exposure to indoor allergens in early infancy and sensitization. J Allergy Clin Immunol 1997;100:177-81.

8. Cullinan P, MacNeill SJ, Harris JM, Moffat S, White C, Mills P, et al. Early allergen exposure, skin prick responses, and atopic wheeze at age 5 in English children: a cohort study. Thorax 2004;59:855-61.
9. Sporik R, Holgate ST, Platts-Mills TA, Cogswell JJ. Exposure to housedust mite allergen (Der p I) and the development of asthma in childhood. A prospective study. N Engl J Med 1990;323:502-7.

10. Belanger K, Beckett W, Triche E, Bracken MB, Holford T, Ren P, et al. Symptoms of wheeze and persistent cough in the first year of life: associations with indoor allergens, air contaminants, and maternal history of asthma. Am J Epidemiol 2003;158:195-202.

11. Polk S, Sunyer J, Munoz-Ortiz L, Barnes M, Torrent M, Figueroa C, et al. A Prospective Study of Fel d1 and Der p1 Exposure in Infancy and Childhood Wheezing. Am J Respir Crit Care Med 2004;170:273-8.

12. Carter PM, Peterson EL, Ownby DR, Zoratti EM, Johnson CC. Relationship of house-dust mite allergen exposure in children's bedrooms in infancy to bronchial hyperresponsiveness and asthma diagnosis by age 6 to 7. Ann Allergy Asthma Immunol 2003;90:41-4.

13. Celedon JC, Litonjua AA, Ryan L, Platts-Mills T, Weiss ST, Gold DR. Exposure to cat allergen, maternal history of asthma, and wheezing in first 5 years of life. Lancet 2002;360:781-2.

14. Remes ST, Castro-Rodriguez JA, Holberg CJ, Martinez FD, Wright AL. Dog exposure in infancy decreases the subsequent risk of frequent wheeze but not of atopy. J Allergy Clin Immunol 2001;108:509-15.

15. Sandin A, Bjorksten B, Braback L. Development of atopy and wheezing symptoms in relation to heredity and early pet keeping in a Swedish birth cohort. Pediatr Allergy Immunol 2004;15:316-22.

16. Nafstad P, Magnus P, Gaarder PI, Jaakkola JJ. Exposure to pets and atopy-related diseases in the first 4 years of life. Allergy 2001;56:307-12.

17. Ownby DR, Johnson CC, Peterson EL. Exposure to dogs and cats in the first year of life and risk of allergic sensitization at 6 to 7 years of age. JAMA 2002;288:963-72.

18. Almqvist C, Egmar AC, Hedlin G, Lundqvist M, Nordvall SL, Pershagen $\mathrm{G}$, et al. Direct and indirect exposure to pets-risk of sensitization and asthma at 4 years in a birth cohort. Clin Exp Allergy 2003;33:1190-7.

19. Gehring U, Triche E, van Strien RT, Belanger K, Holford T, Gold DR, et al. Prediction of residential pet and cockroach allergen levels using questionnaire information. Environ Health Perspect 2004;112:834-9.

20. Crestani E, Guerra S, Wright AL, Halonen M, Martinez FD. Parental asthma as a risk factor for the development of early skin test sensitization in children. J Allergy Clin Immunol 2004;113:284-90.

21. Almqvist C, Egmar AC, van Hage-Hamsten M, Berglind N, Pershagen G, Nordvall SL, et al. Heredity, pet ownership, and confounding control in a population-based birth cohort. J Allergy Clin Immunol 2003;111:800-6.

22. Lakwijk N, Van Strien RT, Doekes G, Brunekreef B, Gerritsen J. Validation of a screening questionnaire for atopy with serum IgE tests in a population of pregnant Dutch women. Clin Exp Allergy 1998;28: 454-8.

23. Brunekreef B, Smit J, de Jongste J, Neijens H, Gerritsen J, Postma D, et al. The prevention and incidence of asthma and mite allergy (PIAMA) birth cohort study: design and first results. Pediatr Allergy Immunol 2002;13:55-60.

24. van Strien RT, Koopman LP, Kerkhof M, Spithoven J, de Jongste JC, Gerritsen J, et al. Mite and pet allergen levels in homes of children born to allergic and nonallergic parents: the PIAMA study. Environ Health Perspect 2002;110:A693-8.

25. Colloff MJ, Ayres J, Carswell F, Howarth PH, Merrett TG, Mitchell EB, et al. The control of allergens of dust mites and domestic pets: a position paper. Clin Exp Allergy 1992;22(suppl 2):1-28.

26. Asher MI, Keil U, Anderson HR, Beasley R, Crane J, Martinez F, et al. International Study of Asthma and Allergies in Childhood (ISAAC): rationale and methods. Eur Respir J 1995;8:483-91.

27. Martinez FD, Wright AL, Taussig LM, Holberg CJ, Halonen M, Morgan WJ. Asthma and wheezing in the first six years of life. The Group Health Medical Associates. N Engl J Med 1995;332:133-8.

28. Brussee JE, Smit HA, Koopman LP, Wijga AH, Kerkhof M, Corver K, et al. Interrupter resistance and wheezing phenotypes at 4 years of age. Am J Respir Crit Care Med 2004;169:209-13.

29. van Strien RT, Koopman LP, Kerkhof M, Oldenwening M, de Jongste JC, Gerritsen J, et al. Mattress encasings and mite allergen levels in the Prevention and Incidence of Asthma and Mite Allergy study. Clin Exp Allergy 2003;33:490-5. 